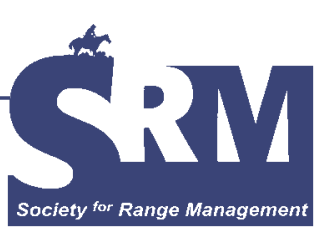

\title{
National Animal Identification and the Elephant in the Room
}

By Rhonda Skaggs and Terry Crawford



urrent interest in individual animal identification arises from a confluence of events: foot-andmouth disease outbreaks in Great Britain, bovine spongiform encephalopathy appearing in Canada and the United States, and the waning influence of older animal identification programs (such as for brucellosis and scrapies eradication). The goal of the planned National Animal Identification System (NAIS) is rapid tracing of animals during an outbreak situation. According to the US Department of Agriculture Animal and Plant Health Inspection Service (USDA-APHIS), the NAIS would help limit the scope and expense of disease outbreaks, reduce negative impacts on domestic and foreign markets, and support ongoing disease eradication efforts.

The current NAIS includes voluntary identification of both individual animals and premises. ${ }^{1}$ A premise is defined in the NAIS as "an identifiable physical location that represents a unique and describable geographic entity where activity affecting the health and/or traceability of animals may occur." According to the NAIS Draft Program Standards, a premise can be a farm, a ranch, another production unit, markets, packing plants, quarantine facilities, ports of entry, veterinary clinics, exhibitions, and so on. The USDA has stated that it is maintaining a technology-neutral position with regard to the technologies that will be used to identify individual animals (or group lots) in the NAIS. However, radio-frequency identification (RFID) ear tags are endorsed for use by the NAIS Cattle Working Group as the "most practical technology" for implementing NAIS in the US cattle industry.

This article has been peer reviewed.

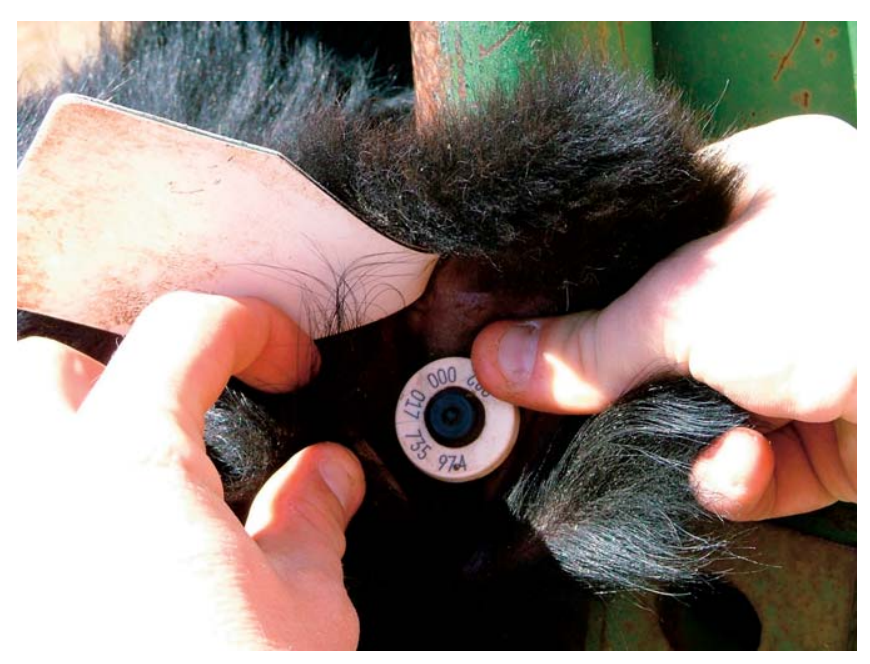

An RFID ear tag. Photo by Shad Cox.

A mandatory NAIS is likely to accelerate pressure for structural change in the US beef/cattle industry to fewer and larger production units, as has happened in the US dairy industry. However, it is our contention that NAIS and its proponents have yet to confront the "elephant in the room" that consists of the deeply ingrained sociocultural aspects of cowcalf production and traditional small-scale lifestyle agriculture in the United States. Advocates of NAIS appear to have an intentionally narrow view of the structure, characteristics, and objectives of a significant portion of the nation's beef cow-calf industry. The objective of this article is to provide insight into the nature of the elephant. This is accomplished using our own and other published data and research. 


\section{Structure and Nature of the US Cow-Calf Pro- duction Sector}

Nationally, almost $80 \%$ of US beef cow-calf operations have fewer than 50 mother cows. ${ }^{2}$ These cattle operations account for $30 \%$ of all reproducing beef cows and heifers. Cattle operations with 50 or more female animals are $20 \%$ of farms with beef calves and heifers that had calved, and they account for almost $70 \%$ of total beef cow and heifer numbers. The USDA considers farms with annual sales of less than $\$ 250,000$ to be small farms. By this criterion, small beef cattle operations account for $89 \%$ of calf sales, $48 \%$ of the total value of US beef cattle production, and control $74 \%$ of the land dedicated to beef cattle production. ${ }^{3}$ The largest category of small farms raising beef cattle are "residential/lifestyle" farms, one of several types of part-time farms identified by the USDA.

Recent research has improved our knowledge and understanding of western US beef cow-calf operators and their motivations for being in ranching. ${ }^{4}$ Data from a random survey of US Forest Service and Bureau of Land Management grazing permittees were used to identify 8 distinct clusters of ranchers. A key attribute for determining a survey respondent's placement in a cluster was based on a spectrum of preferences from ranching as a consumptive behavior (ie, consumption of the ranching lifestyle) to classic profit maximizing, business-oriented behavior. This research identified 2 primary groups of ranchers, hobbyists and professionals, with each comprising approximately $50 \%$ of the total number of survey respondents. The hobbyist group was further divided into 4 subgroups: small hobbyists, retired hobbyists, working hobbyists, and trophy ranchers. The professional rancher group was also divided into 4 subgroups: diversified family ranchers, dependent family ranchers, corporate ranchers, and sheepherders.

The Gentner and Tanaka ${ }^{4}$ study found that the profit motivation for being in ranching was a relatively low ranked objective for all 8 types of ranchers, with consumptive ranching objectives held by all groups. The low ranking of profit motive was particularly strong for the hobbyists and trophy ranchers. However, even diversified and dependent family ranchers and corporate ranchers (who have the highest dependence on ranching income) are strongly motivated to be in ranching for tradition, family, and lifestyle reasons. For all groups of ranchers, consumption motives outranked profit motives.

The National Animal Health Monitoring System (NAHMS) Beef '97 Study stratified respondents into 2 groups: those for whom cow-calf herds were the primary source of family income ( $14 \%$ of respondents) and those producers who keep cattle for supplemental income (69\%) or for some other reason than providing family income (17\%). ${ }^{5}$ Differences in management practices for "primary income" and "nonprimary income" cow-calf producers are striking. Breeding and calving management, animal health, feeding, marketing, and record keeping vary greatly between the 2 types of cow-calf producers, with significantly more inten- sive management practiced by the "primary income" producers. According to the NAHMS results, larger herds are not synonymous with primary income herds.

The NAHMS Beef '97 Study found that $81 \%$ of cowcalf producers kept some form of records, although $79 \%$ were hand-written only. ${ }^{6}$ With respect to identification of individual cows, use of branding (hot iron or freeze) was reported by $7 \%$ of producers, while $46 \%$ reported use of plastic or metal ear tags. Forty-seven percent of the NAHMS cow-calf producers indicated they use no form of individual cow identification, while $52 \%$ reported no identification of individual calves.

Research from other states also indicates relatively low management intensity among livestock producers. For example, a 2005 survey of Wyoming livestock producers found that 53 of 145 respondents (or 36.5\%) used animal identification as an annual management practice. ${ }^{7}$ Results for Montana ranchers who participated in NAHMS were reviewed by Paterson, ${ }^{8}$ who found that $27 \%$ of Montana ranchers make use of data collected from where their calves are finished. In a survey of Iowa beef producers, Lawrence and Schuknecht ${ }^{9}$ found that $25.7 \%$ of cow-calf producers use computerized cow herd performance records.

Our recent survey of $307 \mathrm{New}$ Mexico cow-calf producers found that more than $90 \%$ of the respondents brand their animals and that almost half use ear tags. ${ }^{10}$ Only 1 respondent indicated use of RFID ear tags. Two-thirds of the ranchers who responded to the survey said they did not keep individual animal performance or production records. Ranchers who keep records primarily maintain paper records only. Eight respondents $(2.6 \%)$ stated they use downstream cattle performance data as a management tool. More than half the respondents said their ranching operation was too small for record keeping, and several reported that their memories were sufficient for record keeping.

Overall, the results of our survey, review of other survey results, and other research lead us to conclude that there are low levels of management intensity, interest in individual animal record keeping, and interest in performance analysis on the part of many US cow-calf producers. However, the NAIS is being promoted as worthwhile to livestock producers because of performance record keeping and marketing opportunities (although USDA-APHIS notes that the agency is focused on animal identification as a means to control disease). The assumption that cow-calf producers' business-oriented motivations will lead to widespread voluntary adoption of management intensive animal identification technologies is not supported by data and research on the structure and nature of the cow-calf sector. Furthermore, it is not given that all commercially motivated cow-calf producers are by definition interested in individual animal identification. Some large New Mexico cow-calf producers do not individually identify all or any of their animals because they sell so many calves they don't believe it is cost effective to identify each animal or because they "don't like the look" of ear tags on their cattle. 
Also, our survey of New Mexico cow-calf producers found that one-fifth of the largest ranchers (eg, those with $>200$ head) believes that they are "too small" for individual animal record keeping.

It is interesting to contrast the New Mexico survey results, the NAHMS Beef '97 results, and survey results from other states with a Beef Magazine survey conducted in June 2005. ${ }^{11}$ According to the magazine, $83.4 \%$ of cattle producers who responded to their survey individually identify their cattle, and $12.3 \%$ use electronic ID tags. These results are undoubtedly due to selection bias as a result of a readership that likely includes a large percentage of cattle producers who practice intensive management, have traditional income objectives from ranching, and actively use performance data in their management decisions.

Vendors of electronic animal identification technology strongly emphasize the management benefits of using their technology. The vendors hope that cattle producers are interested in management information that can be collected, cataloged, and analyzed using their technologies. Thus, they are attempting to market their technologies based on attributes above and beyond the data collection necessary for compliance with NAIS. Technology vendors and others assume that in a voluntary identification system, cow-calf operators will be motivated to use electronic animal identification because of the potential benefits of additional productivity data and the possibility that calf buyers are likely to discount cattle that cannot be verified as to source or origin. Vendors and others assume that cattle producers have traditional businessoriented motivations, are concerned about individual animal productivity, and will use such data to create a comparative advantage over other producers. ${ }^{12}$

A mandatory NAIS will require technology and management changes by all cattle producers. Some producers may opt to buy their own electronic identification technology and incorporate management information available through an identification system into their existing management processes. Other producers may choose to contract with a third party (such as a veterinarian or sale barn) for collection and processing of traceability information. Blasi et $\mathrm{a}^{13}$ indicate that the majority of cow-calf operations will likely not be able to economically justify an investment in electronic animal identification technology (which could range from $\$ 4$ to $\$ 25$ per head per year, depending on herd size). Mark ${ }^{14}$ assumes that smaller cow-calf producers will contract with third parties for identification services and estimates that per head costs would be less than $\$ 5$ per head per year under such arrangements.

The cow-calf industry throughout the United States is characterized by a high percentage of small, lifestyle-oriented, consumption-motivated producers. Management-intensive technologies do not have a significant role in these types of cattle operations. Thus, it appears that the technology promoted by NAIS is very inconsistent with the goals of the majority of US cow-calf producers. Indeed, Ishmael, Blasi, and
Spire ${ }^{15}$ have concluded that individual animal ID is worth only what members of the cattle industry can get out of it for their own management purposes. This conclusion is based on those authors' observation that few buyers are demanding or paying for verification of cattle sources and processes. Thus, given the management profile of a large percentage of the US cow-calf industry, we conclude that individual animal ID has little value to them.

NAIS is a critical wedge issue between the commercially or business-oriented segment of the US cattle industry and the lifestyle-oriented segment. Lifestyle-oriented cow-calf producers do not tend to be highly motivated by traditional economic incentives. They have few incentives to adopt many new technologies. Furthermore, natural biological limits in cattle have resulted in few significant productivity increases in beef production over the past century when compared to other livestock species. In the beef cow-calf sector, there are few incentives or opportunities to use, adopt, or exploit technological advances compared to hogs or poultry.

The beef animal is basically a scavenger species. It is still cheaper to let the bull chase the cow through land-extensive production conditions than use artificial insemination. Landextensive production processes are generally not compatible with management-intensive technologies. Increases in management intensity are driven by the need and opportunity to increase returns per unit of input of capital and management. The technological stability of the US cow-calf industry is evidenced by the small change in the average size of a US beef cow herd over the past 30 or so years (from 40 in 1974 to 42 in 2002 according to the US Census of Agriculture).

The US dairy industry continues to move toward increased management intensity and larger-scale farm-level production. Dairy technology changes in the mid-20th century were influenced by changes in the federal milk pricing structure and continuing concern about the human health risks associated with contaminated and/or lower-quality milk. Technology- and policy-driven structural adjustment of the US dairy industry began in approximately 1950 and continues to this day. The average size of a US milk cow herd went from 5 in 1945, to 6 in 1950, to 26 in 1974, and to 99 in 2002 (from the U.S. Census of Agriculture).

Changes in quality control in farm-level milk production were driven by price differentials and health concerns. The result was an upgrading of dairy farm management through technology and education, marketing infrastructure, scientific production practices, Dairy Herd Improvement Association efforts, genetic improvements, artificial insemination, reduction in labor requirements on dairy farms and in milk transportation and processing, and concentration in the dairy industry. Retailing shifted from home delivery of bottled milk to an integrated national market for fluid milk and milk products. Assembly of dairy products in the United States is now accomplished with much larger and efficient units than at any time in history. Basically, multiple factors led to adoption of advanced technology throughout the US dairy 
industry. Yet even with all the forces for technology upgrading in the US dairy industry over the past half century, a 2002 survey of Vermont dairy farms found pail systems still used on $7.5 \%$ of the state's dairy farms. ${ }^{16}$

Boxed beef can be viewed as a parallel technological and market advance similar to the advent of refrigerated bulk tank Grade A milk handling. Boxed beef is an efficiency increasing technology that reduces uncertainty and reduces transport, handling, and meat-cutting costs throughout the marketing chain and increases product uniformity at the end of the marketing chain. Segmentation of retail beef marketing has been the end result. While some may argue that the quality of individual beef cuts has decreased as a result of changes in the grading system, overall beef product consistency has been enhanced and real prices have been reduced as a result of boxed beef technology. The feedlot and packing sectors have dramatically increased in size and concentration to achieve economies of scale. However, similar structural adjustment at the cow-calf producer level has not occurred. Most of the advances in technology and increases in efficiency in the beef industry have occurred beyond the farmgate.

Narrow adoption of "sophisticated" production technologies, limited increases in cow-calf producer efficiency measures, and the continued small average herd size can be attributed to the physiology of the beef animal, land-extensive production processes, as well as the lifestyle or consumptive motivations of many cow-calf producers. A large number of cow-calf producers are not primarily motivated to maximize production or profits, particularly if these objectives conflict with lifestyle, values, or ethical choices. Because of the diversity of firms and motivations within the US cattle industry, NAIS needs to accommodate many conflicting objectives. However, NAIS currently appears to be directed to the interests of the beef and cattle industry beyond the farmgate (or ranch). In a voluntary NAIS, cow-calf sector structure, diversity, and cost issues will be major impediments to system implementation. If NAIS becomes mandatory, we are likely to see a titanic culture clash between different segments of the US beef and cattle industry. We suspect that small-scale, traditional, residential/lifestyle, hobbyist, consumptive behavior cattle producers will not fade away as quietly or as quickly as small-scale dairy producers did in the face of nonstructurally neutral technology mandates.

If NAIS is to have any chance of success in the US cowcalf industry, it needs to put action into its oft-stated position of technological neutrality by working to include older, cheaper, more cost-effective identification and reporting technologies in the system. At the current time, RFID is the technology of choice, yet there is little evidence that any other technologies have been considered for the NAIS. Promoters of animal identification seemingly have a bias in favor of the latest technological innovation, such as RFID, biometric screening, and DNA typing, rather than simpler technologies that would be more appropriate for and acceptable to a wider range of cattle producers. This suggests that NAIS proponents have objectives in addition to rapid traceback in the event of a disease outbreak.

Authors are Professor, Department of Agricultural Economics and Agricultural Business, New Mexico State University, Las Cruces, NM 88003,rskaggs@nmsu.edu (Skaggs); and College Professor, Department of Agricultural Economics and Agricultural Business, Nerw Mexico State University, Las Cruces, NM 88003 (Crawford).

\section{References}

1. USDa Animal and Plant Health Inspection Service. 2006. National Animal Identification System (NAIS). A User Guide and Additional Information Resources. Draft version. November. Available at: http://animalid.aphis.usda.gov/nais/ naislibrary/documents/guidelines/User_Guide.html. Accessed 1 March 2007.

2. USDa National Agricultural Statistics Service. 2004. 2002 Census of agriculture, US data. Available at: http://www. nass.usda.gov/census/census02/volume1/us/st99_1_012_013. pdf. Accessed 21 June 2006.

3. CAsh, A. J. 2002. Where's the beef? Small farms produce majority of cattle. Agricultural Outlook, USDA Economic Research Service, pp. 21-24. December. Available at: http://www. ers.usda.gov/publications/agoutlook/Dec2002/ao297g.pdf. Accessed 21 June 2006.

4. Gentner, B. J., and J. A. Tanaka. 2002. Classifying federal public land grazing permittees. Journal of Range Management 55:2-11.

5. USDa Animal and Plant Health Inspection Service Veterinary Services. 1998. Importance of income in cowcalf management and productivity. September. Available at: http://nahms.aphis.usda.gov/beefcowcalf/beef97/bf97income. pdf. Accessed 21 June 2006.

6. USDA Animal and Plant Health Inspection Service Veterinary Services. 1998. National Animal Health Monitoring System (NAHMS). Part IV: Changes in the U.S. beef cow-calf industry, 1993-1997. May. Available at: http://nahms. aphis.usda.gov/beefcowcalf/beef97/bf97pt4.pdf. Accessed 21 June 2006.

7. Sarchet, B. A. 2005. Pilot survey and analysis of Wyoming cattle production (2004). May. Department of Agricultural and Applied Economics, University of Wyoming, Laramie, WY. Available at: http://agecon.uwyo.edu/WYLivestock/ 2005_05_03_Report_PartA.pdf. Accessed 21 June 2006.

8. Paterson, J. No date. Management of the cow herd: Survey responses of the Montana and U.S. rancher. Animal and Range Sciences Department, Montana State University, Bozeman, MT. Available at: http://www.animalrangeextension.montana. edu/Articles/Beef/herd_mgt.htm. Accessed 21 June 2006.

9. Lawrence, J. D., and S. Schuknecht. No date. Iowa beef producer profile, 2005: A survey of Iowa cow-calf and feedlot owners by the Iowa Beef Center. Iowa Beef Center at Iowa State University, Ames, IA. Available at: http://www. 
iowabeefcenter.org/content/2005SurveyReport.pdf. Accessed 21 June 2006.

10. Skaggs, R., And Crawford, T. In press. Livestock identification in New Mexico: Current status and implications for national animal identification. New Mexico State University Agricultural Experiment Station Research Bulletin.

11. Beef Magazine. 2005. What you told us. July. Available at: http://beef-mag.com/mag/beef_told_us/. Accessed 21 June 2006.

12. BeefStocker USA. 2005. Beef Stocker USA 2005 survey of the animal identification industry. Available at: http:// beefstockerusa.org/rfid/grid.htm. Accessed 21 June 2006.

13. Blasi, D. A., K. C. Dhuyvetter, M. F. Spire, M. P. Epp, and B. B. Barnhardt. 2003. A guide for electronic identification of cattle. Kansas State University Agricultural Experiment Station and Cooperative Extension Service.
14. Mark, D. R. 2004. Effects of animal identification on cattle market structure. Western Extension Marketing Committee, Livestock Marketing Information Center, and Western Center for Risk Management Education WEMC FS\#9-04. Available at: http://www.lmic.info/memberspublic/animalID/IDframe. html. Accessed 21 June 2006.

15. Ishmael, W., D. Blasi, and M. Spire. 2005. Management drives I.D. decisions. Stocker Facts, a product of BeefStockerUSA.org. April. Available at: http:// beefstockerusa.org/factsheets/ManagementDrives.pdf. Accessed 1 March 2007.

16. Parsons, B. 2003 (February). Survey looks at technology use On Vermont's farms. Agriview Online 67(4, April). Available at: http://www.uvm.edu/extension/agriview/av03feb15bp.htm. Accessed 1 March 2007. 